\title{
Numerical Forecasting Experiment of the Wave Energy Resource in the China Sea
}

\author{
Chong Wei Zheng, ${ }^{1,2,3}$ Chong Yin Li, ${ }^{1,2}$ Xuan Chen, ${ }^{2}$ and Jing Pan ${ }^{1}$ \\ ${ }^{1}$ National Key Laboratory of Numerical Modeling for Atmospheric Sciences and Geophysical Fluid Dynamics (LASG), \\ Institute of Atmospheric Physics, Chinese Academy of Sciences, Beijing 100029, China \\ ${ }^{2}$ College of Meteorology and Oceanography, People's Liberation Army University of Science and Technology, Nanjing 211101, China \\ ${ }^{3}$ Dalian Naval Academy, Dalian 116018, China
}

Correspondence should be addressed to Chong Yin Li; lcy@lasg.iap.ac.cn

Received 29 January 2016; Revised 4 June 2016; Accepted 29 June 2016

Academic Editor: Mariana Bernardino

Copyright (C) 2016 Chong Wei Zheng et al. This is an open access article distributed under the Creative Commons Attribution License, which permits unrestricted use, distribution, and reproduction in any medium, provided the original work is properly cited.

\begin{abstract}
The short-term forecasting of wave energy is important to provide guidance for the electric power operation and power transmission system and to enhance the efficiency of energy capture and conversion. This study produced a numerical forecasting experiment of the China Sea wave energy using WAVEWATCH-III (WW3, the latest version 4.18) wave model driven by T213 (WW3-T213) and T639 (WW3-T639) wind data separately. Then the WW3-T213 and WW3-T639 were verified and compared to build a shortterm wave energy forecasting structure suited for the China Sea. Considering the value of wave power density (WPD), "wave energy rose," daily and weekly total storage and effective storage of wave energy, this study also designed a series of short-term wave energy forecasting productions. Results show that both the WW3-T213 and WW3-T639 exhibit a good skill on the numerical forecasting of the China Sea WPD, while the result of WW3-T639 is much better. Judging from WPD and daily and weekly total storage and effective storage of wave energy, great wave energy caused by cold airs was found. As there are relatively frequent cold airs in winter, early spring, and later autumn in the China Sea and the surrounding waters, abundant wave energy ensues.
\end{abstract}

\section{Introduction}

In the current world where human beings are severely plagued by the problems of environment and resources, full exploitation and utilization of new energy resources will effectively alleviate the energy crisis and contribute to global energy-saving, emission reduction, and environmental protection, thus promoting sustainable development. Abundant wave energy has become a particular area of interest for all developed countries [1-4]. Previous studies have made great contributions to the development of wave energy resources [5-9]. The use of observational data and numerical simulation to assess and divide the class of the wave energy resource has provided better references for site selection of wave energy development, for example, wave power plant location. Akpinar and Kömürcü [10] have analyzed the Black Sea wave energy resource based on 15-year hindcast data by using the
SWAN (Simulated WAves Nearshore) wave model. Applying the SWAN wave model, Neill and Hashemi [11] made an assessment of the offshore wave energy in Northwestern Europe. The results suggest that wave energy resources in the area have a relatively close relationship with the North Atlantic Oscillation (NAO). In 2009, Roger [12] carried out offshore wave energy forecasting in the East Pacific using the WW3 wave mode. Comprehensively considering the value and stability of the WPD, energy level frequency, and resource reserve, Zheng et al. $[13,14]$ have analyzed the overall characteristics of the China Sea wave energy resource. Results show that while the China Sea is not located in areas with the most abundant wave energy, they do contain suitable wave energy resources for exploitation, especially in the East China Sea and the northern South China Sea. Zheng and Li [15] have revealed the climatic long-term trends of the China Sea wave power and significant wave height (SWH) for the 
period 1988-2011 based on 24-year hindcast wave data, which can provide reference for the long-term plan of wave energy resource development.

Most of the previous researches focus on the evaluation of the wave energy climatic characteristics rather than numerical forecasting. Assessment of wave energy resource can provide a reference for site selection of wave energy development (such as wave power plant location). But until now, there is little research on the forecasting of the China Sea wave energy resource. After a power generating device is installed, the wave energy forecasting is especially important to provide routine support to enhance the efficiency of energy capture and conversion. As there are relatively frequent cold airs in winter, early spring, and late autumn in the China Sea and the surrounding waters, abundant wave energy ensues. Accurate forecasting of wave energy will make contribution to the development of wave energy resource.

Previous researchers have made great contribution to the numerical wave model. In the previous researches, the reanalysis wind data is usually used to force the numerical wave model to simulate the past wave field, which overall results in a good simulation outcome attribute to the relative high precision of the reanalysis wind data. However, in the process of numerical forecasting of the future wave energy, the driven field is forecasting wind data. The quality of forecasting wind data is usually not as good as the reanalysis wind data, which may greatly increase the difficulty of wave energy forecasting. In this study, we produced a numerical forecasting experiment of the China Sea wave energy during two cold air processes on 12-17 March 2013, using WW3 wave model driven by T213 (WW3-T213) and T639 (WW3T639) wind data separately. Then the WW3-T213 and WW3T639 were verified and compared to build a short-term wave energy forecasting structure suited for the China Sea. We also designed a series of short-term wave energy forecasting productions, including the size of WPD, "wave energy rose," daily total storage of wave energy, daily effective storage of wave energy, and total storage and effective storage of wave energy. We hope this work can provide reference for the development of wave energy and alleviate the energy crisis, as well as contributing to emissions reduction and environmental protection, and so promote future sustainable development.

\section{Methodology and Data}

2.1. Numerical Simulation Method of Wave Energy. This study aims to build a numerical forecasting structure of wave energy suited for the China Sea. Two strong cold air processes for the period 8 to 16 March 2013 were selected to produce a numerical forecasting experiment. Firstly, the WW3 (the latest version 4.18) wave model was driven by T213 (WW3T213) and T639 (WW3-T639) wind data separately. Then the WW3-T213 and WW3-T639 were verified and compared. Considering the value of wave power density (WPD), "wave energy rose," and daily and weekly total storage and effective storage of wave energy, this study also designed a series of short-term wave energy forecasting productions.

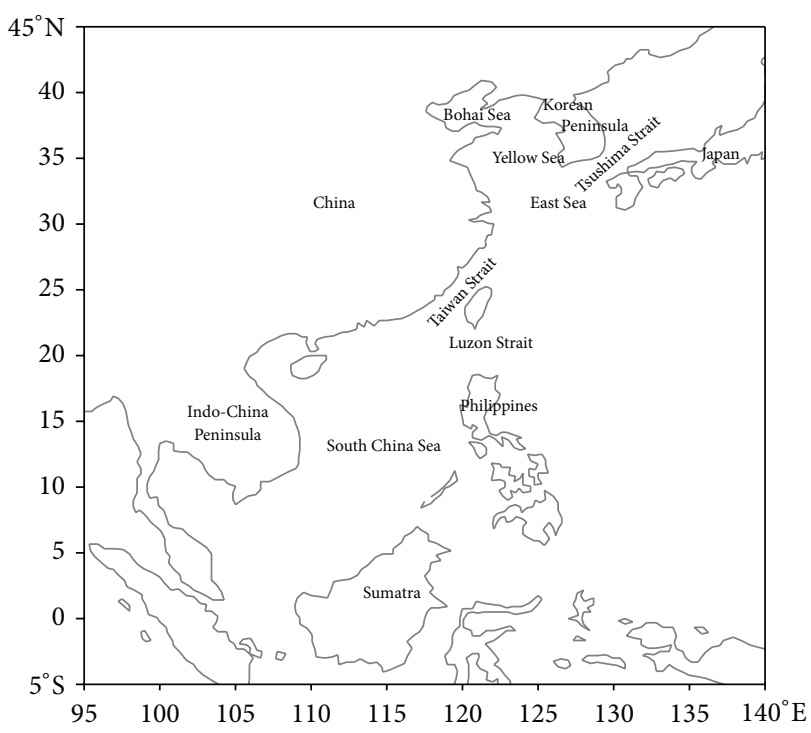

FIgURE 1: Topography of the China Sea and surrounding waters.

The related calculation data are as follows: in order to eliminate the boundary effect to improve the precision of simulation wave data, we set the simulating area as $10^{\circ} \mathrm{S} \sim 55^{\circ} \mathrm{N}$, $95^{\circ} \mathrm{S} \sim 160^{\circ} \mathrm{E}$ and then extract concerned area as $0^{\circ} \sim 41^{\circ} \mathrm{N}, 100^{\circ} \sim$ $135^{\circ} \mathrm{E}$ which contains the main part of the China Sea and surrounding waters; the topography is shown in Figure 1. The value of $0.1^{\circ} \times 0.1^{\circ}$ was taken as the spatial resolution. The duration of $300 \mathrm{~s}$ was taken as the time step of calculation. The results were outputted each hour. The computing time was from 00:00 8 March 2013 to 21:00 18 March 2013.

2.2. Wave Power Density Calculation Method. Wave power density calculation method is as follows [16-18].

In shallow water, calculation method is as follows:

$$
P_{w}=\frac{\rho g}{16} H_{s}^{2} \sqrt{g d} .
$$

In deep water, calculation method is as follows:

$$
P_{w}=\frac{\rho g^{2}}{64 \pi} H_{s}^{2} T_{e}=0.49 H_{s}^{2} T_{e}
$$

where $P_{w}$ is wave power density (unit: $\mathrm{kW} / \mathrm{m}$ ), $H_{s}$ is the significant wave height (unit: $\mathrm{m}$ ), $T_{e}$ is the energy period (unit: s), and $d$ is the water depth.

2.3. Wind Field Data and Topographic Data. Topographic data input of the wave model is obtained from the ETOPO1 high resolution data set of global ocean of NOAA $\left(1^{\prime} * 1^{\prime}\right)$, and the coastline data was obtained from the GSHHS global high resolution coastline database.

The T213 and T639 forecasting wind data were used as the driving field of the WW3 wave model separately. The T213 model was introduced from ECMWF in 1997. The T213 model has 31 vertical resolution layers, with top of $10 \mathrm{hpa}$. The spatial resolution is $0.5625^{\circ} \times 0.5625^{\circ}$. T639 is the abbreviation of the global medium-term numerical weather prediction 


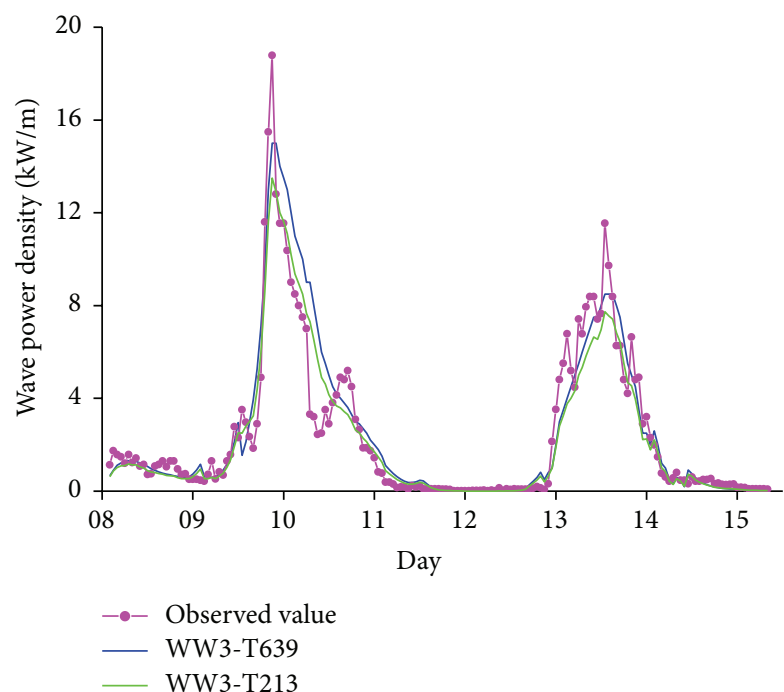

(a)

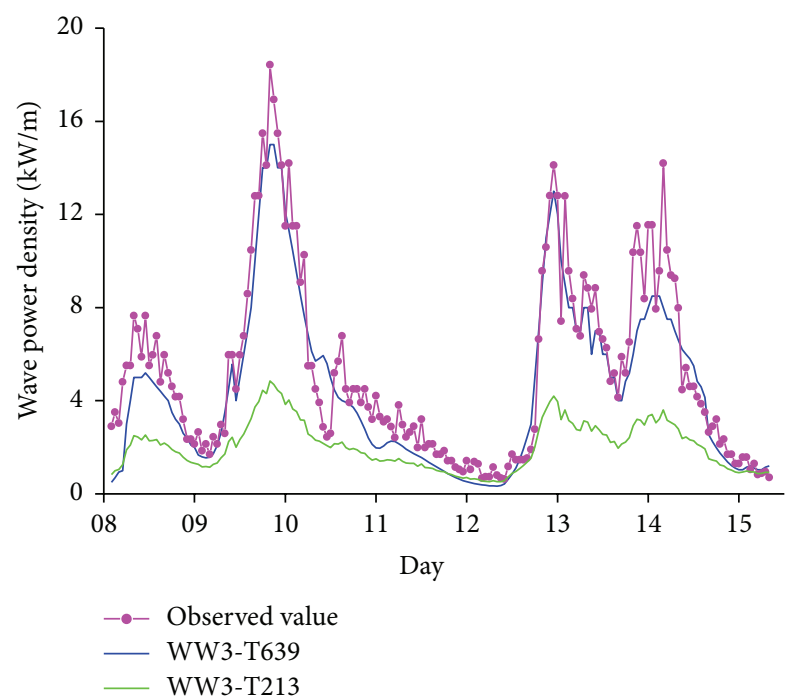

(c)

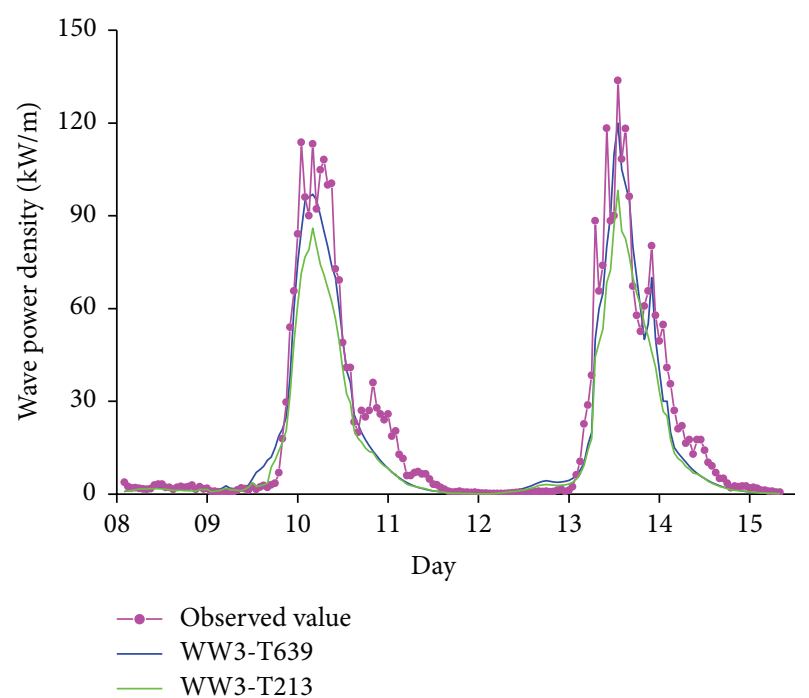

(b)

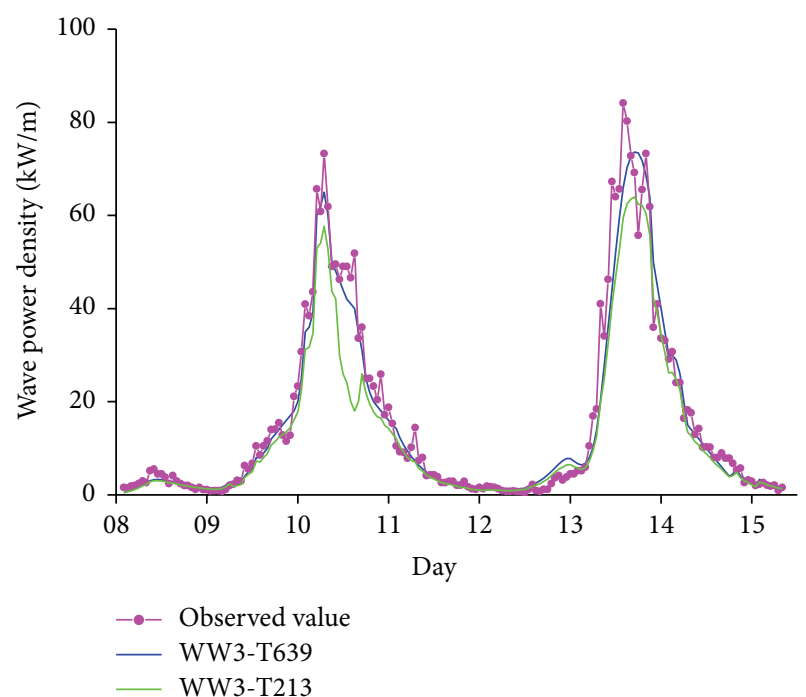

(d)

FIGURE 2: Observed and forecasting wave power density in March 2013 around the Korean Peninsula. (a)-(d): denoting stations 22101, 22102, 22103, and 22017.

model improved from T213. Compared to the T213 product, the T639 data has the advantages of factor abundance and high temporal-spatial resolution [19]. The T639 mode has 60 vertical resolution layers. The temporal resolution is 3 hours. The spatial resolution is $0.3^{\circ} \times 0.3^{\circ}$. The spatial scope covers the entire Northern Hemisphere. The mode was put into operation in 2008 by the National Meteorological Center of China. In addition, Ma et al. [20] have also found that the T639 model can depict the tropical cyclone much better than the T213 model.

2.4. Observed Wave Data. Currently, the worldwide observed wave data is relatively scarce, especially in China. There are no NDBC buoys in the China Sea. Although the accuracy of the significant wave height from the satellite is widely recognized, the number of satellite orbits over the China Sea is small and the repetition period is long (e.g., the $T / P$ altimeter cycle is $10 \mathrm{~d}$ ). This results in many drawbacks that the wave data from satellite is short in spatial resolution and temporal resolution $[13,14]$. In light of the shortage of observed wave data, we extensively collected buoy data from the South Korea, Japan, and Chinese Taiwan Region to verify the effectiveness of the forecasting data.

\section{Validation of the Forecasting Wave Power Density}

Comparing the curves of the forecasting WPD and the observed WPD, it is possible to visually make out the accuracy of the forecasting data, as shown in Figures 24. During the two processes of cold air invasion, in the waters surrounding the Korean Peninsula, Japan, and Taiwan 


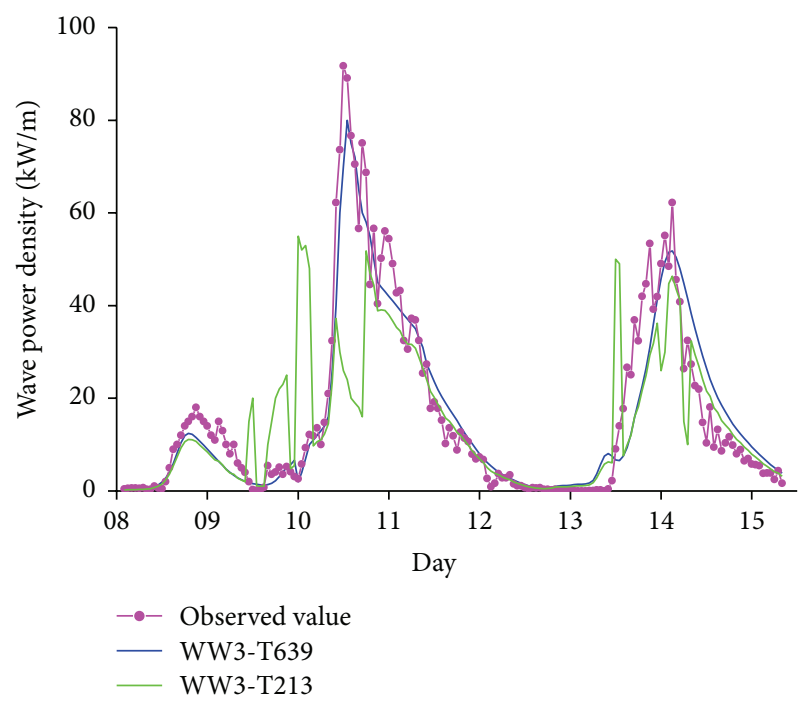

(a)

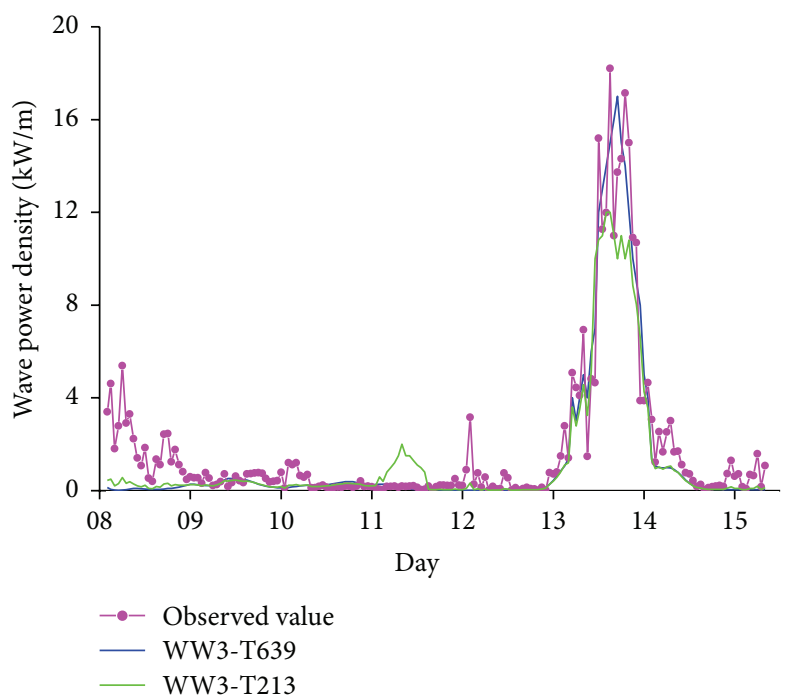

(c)

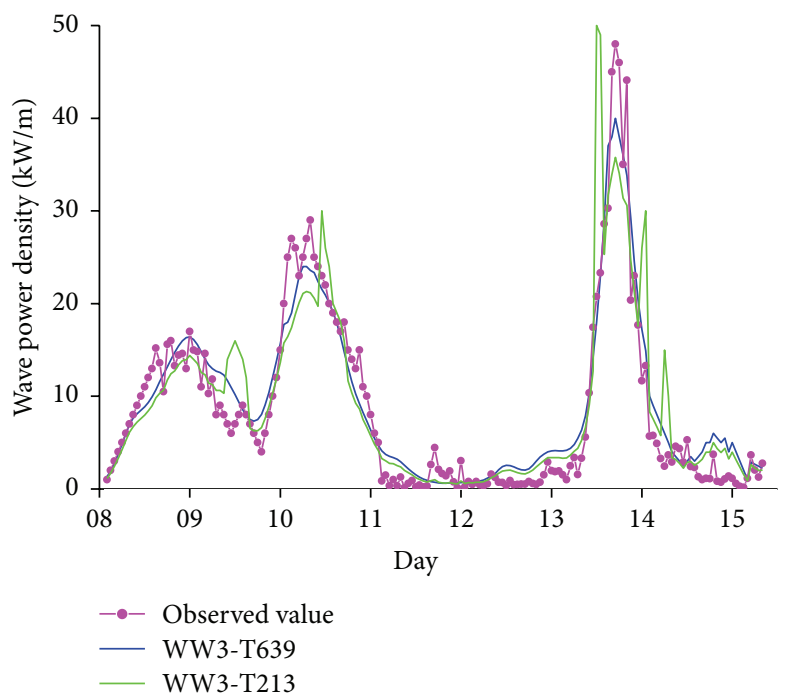

(b)

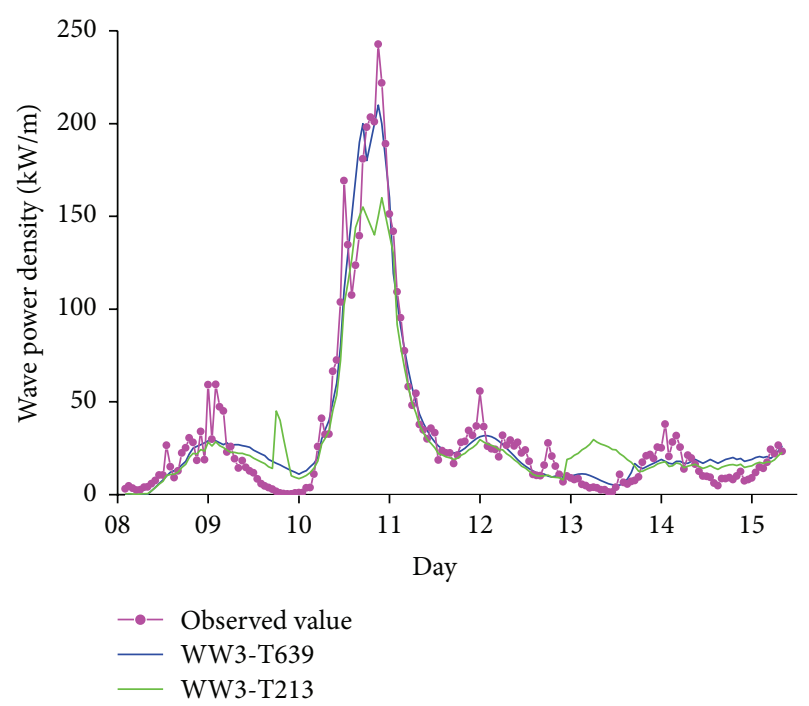

(d)

FIGURE 3: Observed and forecasting wave power density in March 2013 around Japan. (a)-(d): denoting stations Kyogamisaki, Irozaki, Karakuwa, and Kaminokuni.

Island, the forecasting and observed WPD exhibit a good consistency. And the observed value is slightly larger than the forecasting value. The observed WPD curve shows noticeable jumpy phenomenon while the forecasting WPD curve appears slightly smooth.

In the waters surrounding the Korean Peninsula (Figure 2), judging from the trend of the curves of the forecasting and observed values, they are in better agreement with each other. The WPD of WW3-T639 is closer to the observed WPD at each station, while the WPD of WW3-T213 is smaller than the WPD of WW3-T639, especially at station 22103 during the second cold air process. The forecasting values are able to effectively demonstrate the course of the increase in the WPD caused by two processes of cold air invasion, especially that for the first process of cold air invasion (10 March 2013). During the cold air invasion period, the forecasting WPD is slightly smaller than the observed data, suggesting that the measured WPD is richer than the forecasting data. Obviously, the cold air process can bring very rich wave energy to the waters of stations 22102 and 22107, of up to $120 \mathrm{~kW} / \mathrm{m}$, while the wave energy caused by the cold air at stations 22101 and 22103 is smaller, which can be attributed to the effect of geography characteristic. In the development of wave energy, WPD greater than $2 \mathrm{~kW} / \mathrm{m}$ is regarded as available and greater than $20 \mathrm{~kW} / \mathrm{m}$ is regarded as rich. It is clear that the growth of wave energy caused by the cold air process is promising.

In the waters surrounding Japan (Figure 3), the trend of the curves of the forecasting values and observed values also retained relatively good consistency. There is a good agreement between the observed WPD and WPD of WW3-T639. The WPD of WW3-T213 has obvious jumping 

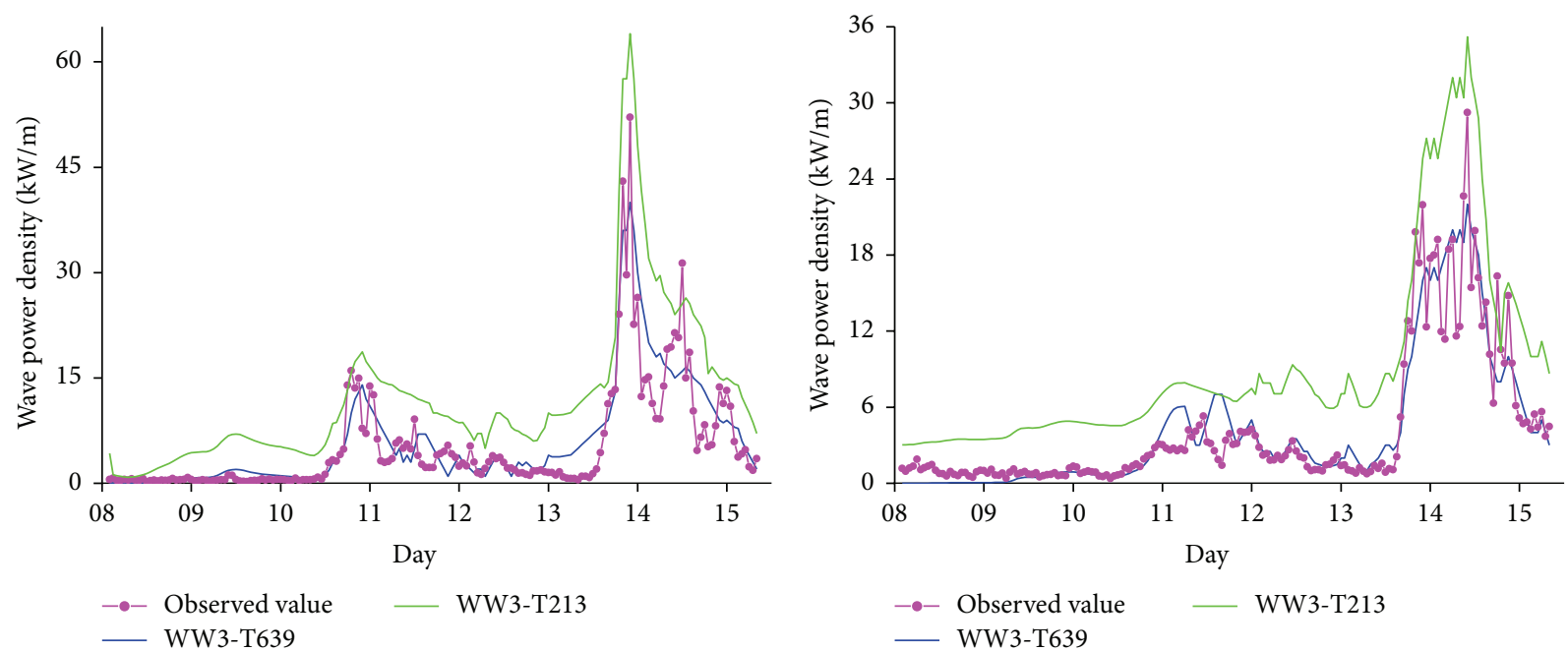

(a)

(b)
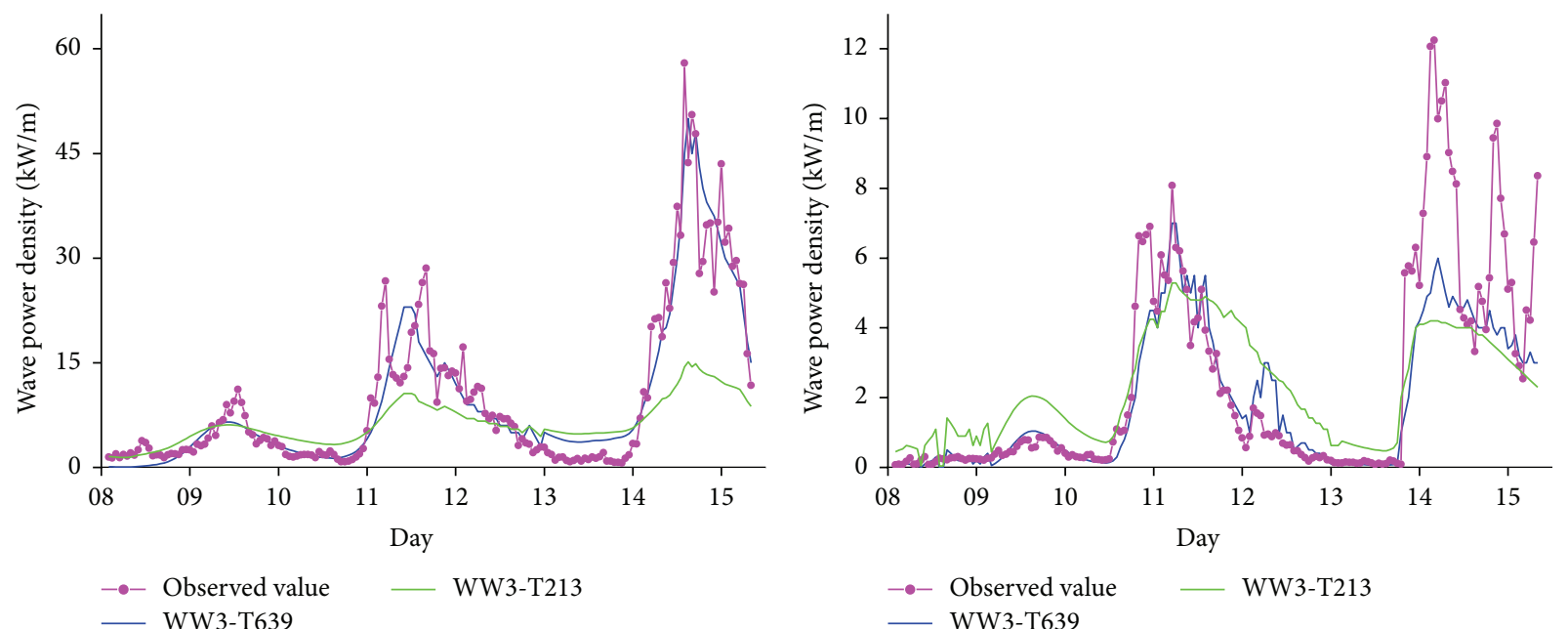

(c)
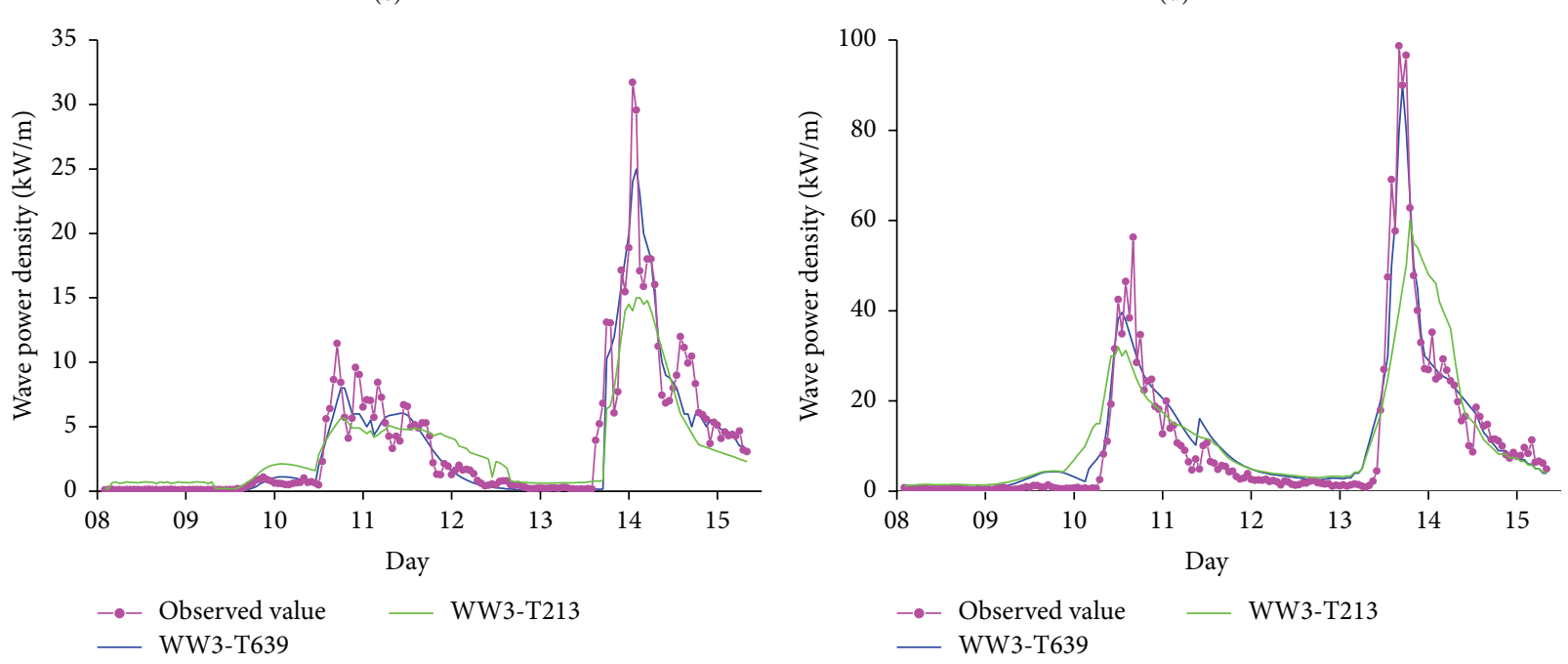

(e)

(f)

FIGURE 4: Observed and forecasting wave power density in March 2013 around the Taiwan Island. (a)-(f): denoting stations Longdong, Hualian, Dongsha, Qigu, Jinmen, and Mazu. 
phenomenon, which results in a larger error. The WPD increased to $80 \mathrm{~kW} / \mathrm{m}$ at station Kyogamisaki, to $40 \mathrm{~kW} / \mathrm{m}$ at stations Irozaki, and even up to about $250 \mathrm{~kW} / \mathrm{m}$ at station Kaminokuni. The cold airs do not affect station Karakuwa significantly, especially the period of the first cold air invasion. This should be due to the effect of topography.

There is an excellent agreement between the forecasting and observed WPD at all stations in the waters surrounding Taiwan Island, except Qigu station, as shown in Figure 4. Obviously, the relationship between observed WPD and WPD of WW3-T639 is much better than that between observed WPD and WPD of WW3-T213. The noticeable error of forecasting value may be due to the block on the wave field of Taiwan Island. In the waters surrounding the islands like stations Longdong, Dongsha, and Mazu, the WPD could increase to $60-80 \mathrm{~kW} / \mathrm{m}$ under the influence of cold air; particularly in station Mazu, the WPD can be up to $100 \mathrm{~kW} / \mathrm{m}$ during the period of the second cold air invasion. In the regions surrounding stations Hualian and Jinmen, the WPD could increase to $30-40 \mathrm{~kW} / \mathrm{m}$ during the cold air invasion period.

In order to analyze the accuracy of the forecasting WPD quantitatively, we also calculated the correlation coefficient (CC), Bias error, root mean square error (RMSE), and mean absolute error (MAE), as shown in Table 1.

From the correlation coefficient (CC), the forecasting and observed WPD have good correlation (significant at the 99\% level) regardless of the sea areas surrounding the Korean Peninsula, Japan, or Chinese Taiwan Region. The CC between observed WPD and WPD of WW3-T639 is above 0.90 at each station, while the CC between observed WPD and WPD of WW3-T213 is obviously smaller. It is also worth noting that the forecasting results of the WW3 mode in the sea areas surrounding the Korean Peninsula and Japan are relatively better than that in the sea area surrounding Taiwan Island. About the Bias, RMSE, and MAE, the errors are relatively small at most stations. Only the errors in the sea area at stations 22102, 22107, Kyogamisaki, Kaminokuni, and Mazu are relatively large but within the acceptable range, because the wave power densities at these 5 stations are remarkably larger than that at other stations (as shown in Figures 24). From the Bias, the forecasting WPD is overall smaller than the observed values, meaning that the actual wave energy is more optimistic than the forecasting condition. As a whole, the forecasting WPD is more accurate, suggesting that the WW3 model can appropriately simulate the China Sea WPD under the influence of two processes of cold air invasion. Previous researches also proved a good skill of WW3 wave model on the numerical simulation of the China Sea wave field $[13,14,21-23]$. The results of this paper provide confirmatory evidence that the WW3 wave model can accurately forecast the China Sea WPD very well.

\section{Forecasting of Wave Energy}

4.1. Spatial-Temporal Distribution of the Forecasting Wave Power Density. Based on the simulation wave data and calculation method of WPD, the hourly China Sea WPD from 00:00 on 8 March 2013 to 21:00 on 18 March 2013 is obtained. The spatial-temporal distribution characteristics of the forecasting WPD field in the period of cold air invasion are presented in Figure 5. At 12:00 on 12 March, the cold air moved into the Bohai Sea, bringing about a WPD of over $40 \mathrm{~kW} / \mathrm{m}$ in most of the Bohai Sea. In the center with high values, the density can even be up to $80 \mathrm{~kW} / \mathrm{m}$. At 12:00 on 13 March, the cold air moved into the mid-south area of the Yellow Sea, and the WPD induced is from 50 to $120 \mathrm{~kW} / \mathrm{m}$. At 12:00 on 14 March, when the cold air moved into the Ryukyu Islands waters, the waters became opener; a wide range of significant waves grew fully, resulting in the enlargement of the range of WPD greater than $40 \mathrm{~kW} / \mathrm{m}$. At 12:00 on 15 March, cold air moved into the Taiwan Island waters. The scale of WPD greater than 40 continues to broaden. At 12:00 on 16 March, cold air moved into the north area of the South China Sea, bringing about a cold surge. However, because the latitude of the South China Sea is lower, the strength of the cold air was greatly weakened after the air entered therein so that the scope with the WPD above $40 \mathrm{~kW} / \mathrm{m}$ was apparently shrunken. At 12:00 on 17 March, the cold air moving into the mid-south area of the South China Sea generated apparent cold surge and increasing process of the WPD, but the intensity is not as strong as that in the East China Sea and the northern South China Sea.

It is usually assumed that areas with WPD greater than $20 \mathrm{~kW} / \mathrm{m}$ can be classified as energy-rich regions, such as the North Sea in Europe. From Figure 5, it is very clear that the cold air can result in a WPD of $>20 \mathrm{~kW} / \mathrm{m}$ in large scale area. Even more, as there are relatively frequent cold airs in winter, early spring, and late autumn in the China Sea and the surrounding waters, abundant wave energy ensues.

4.2. Forecasting of Wave Energy Storage. Calculating the storage of energy can provide decision-making for the electric power operation and power transmission system. In this present study, the per-unit-area total storage, effective storage, and technological storage of the China Sea wave energy at each $0.1^{\circ} \times 0.1^{\circ}$ bin were obtained. We mainly calculated the daily total storage of wave energy (Figure 6), daily effective storage of wave energy (Figure 7), and daily exploitable storage of wave energy (figure omitted) from 12 to 17 March 2013. The total storage and effective storage of wave energy in the next week start from 12 March 2013 were also exhibited, as shown in Figure 8.

The energy storage calculation method is as follows:

$$
\begin{aligned}
& E_{P T}=\bar{P} * H, \\
& E_{P E}=\bar{P} * H_{E}, \\
& E_{P D}=E_{P E} * C_{e},
\end{aligned}
$$

where $E_{P T}$ is the daily total storage of wave energy, $\bar{P}$ is the daily average WPD, and $H=24 \mathrm{~h}$ in one day. In (4), $E_{P E}$ is the daily effective storage of wave energy and $H_{E}$ is the hours of effective significant wave height in one day. In (5), $E_{P E}$ is the daily technological development volume of wind energy resources, showing some discrepancy along with 


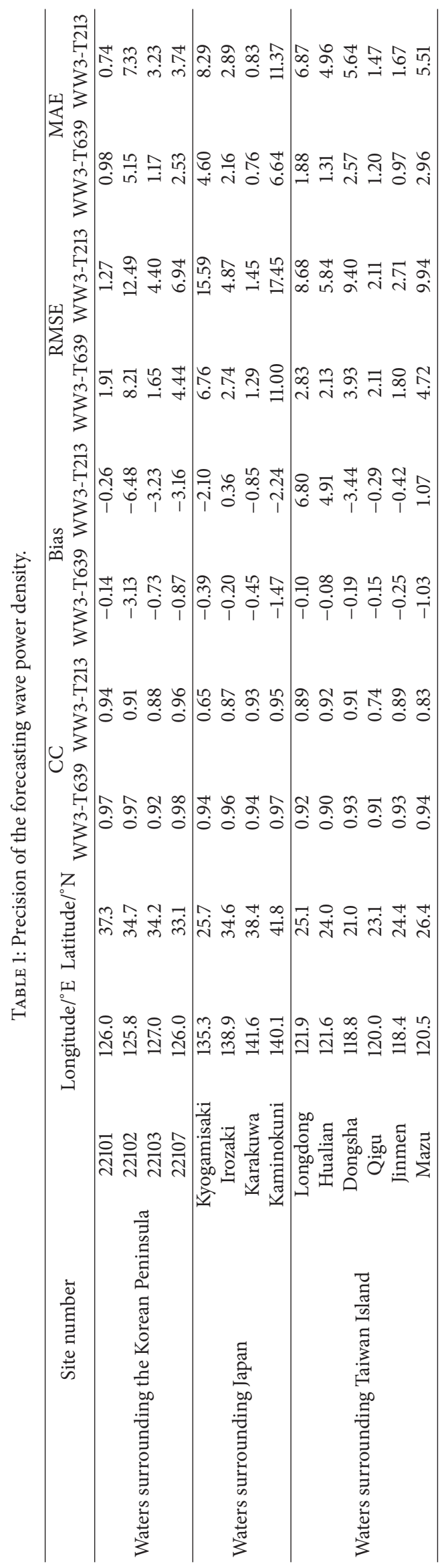



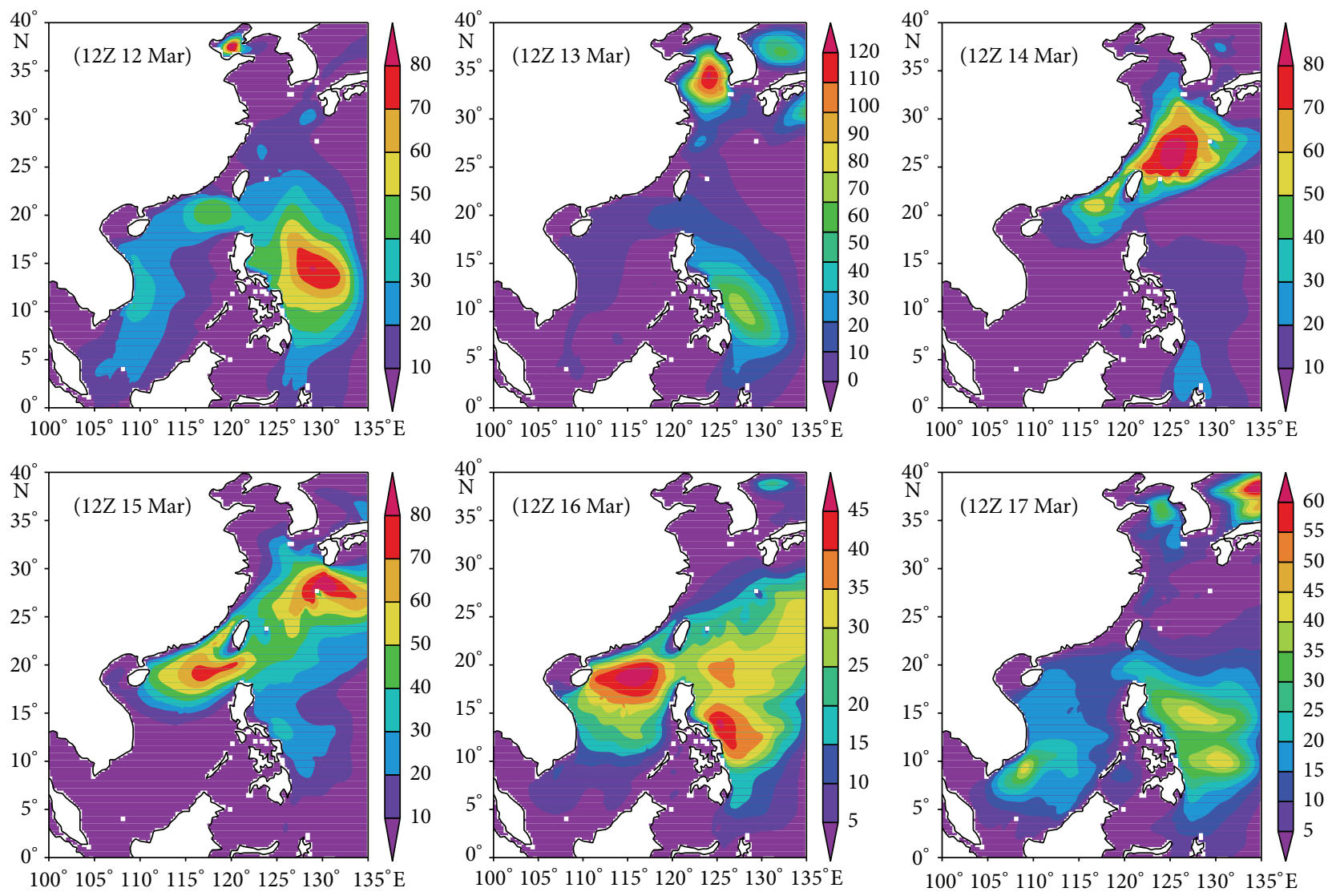

FIgURE 5: Wave power density in the China Sea during the cold air process in March 2013, unit: kW/m.

the difference of installation. $C_{e}$ is the absorption ability of installation.

As shown in Figure 6, the cold air brings wave energy storage of $400-800 \mathrm{kWh} / \mathrm{m}$ on 12 March in the Bohai Sea. On 13 March, the cold air moved into the Yellow Sea, resulting in a rapid increase in the wave energy storage, of $>800 \mathrm{kWh} / \mathrm{m}$ in most areas of the Yellow Sea and even greater than $1800 \mathrm{kWh} / \mathrm{m}$ in the large center. On $14 \mathrm{March}$, when the cold air moves into the East Sea, with the broader of waters, a wide range of significant waves grew fully. The scales of wave energy storage $>800 \mathrm{kWh} / \mathrm{m}$ and $>1800 \mathrm{kWh} / \mathrm{m}$ enlarge significantly. On 15 March, with the cold air moving into the Taiwan Island waters, the scale of wave energy storage $>800 \mathrm{kWh} / \mathrm{m}$ continues to broaden. On $16 \mathrm{March}$, the cold air moved into the north area of the South China Sea, where the wave energy storage is $600-1200 \mathrm{kWh} / \mathrm{m}$. On $17 \mathrm{March}$, the cold air moving into the mid-south area of the South China Sea generated wave energy storage of $400-600 \mathrm{kWh} / \mathrm{m}$, for the intensity is not as strong as that in the East China Sea and the northern South China Sea.

From Figure 7, we find that there is a good agreement between the daily effective storage of wave energy and daily total storage of wave energy daily (Figure 6). This should be due to the high occurrence of the significant wave height $>1.0 \mathrm{~m}$.

The total storage and effective storage of wave energy in the next week start from 12 March 2013 were presented in
Figure 8. The total storage of wave energy is promising during this cold air process, of $>2000$ in large scale of the China Sea. The large areas are mainly distributed in the middle of the Yellow Sea, Ryukyu Islands waters, north of the South China Sea, and east nearshore of Philippine, of above $4000 \mathrm{kWh} / \mathrm{m}$ and even greater than $6000 \mathrm{kWh} / \mathrm{m}$ in the large center. The distribution characteristic of effective storage is similar to that of total storage, due to the high occurrence of the significant wave height $>1.0 \mathrm{~m}$ during the cold air process.

4.3. Station Forecasting. In the development of wave energy resource, we usually pay more attention to the energy condition at some certain sites. For the sake of providing reference for the electric power operation, we produced station forecasting of wave energy. Here, we select two stations at will as the study object: station $\mathrm{A}\left(30^{\circ} \mathrm{N}, 130^{\circ} \mathrm{E}\right.$, at the Tsushima Strait) and station $\mathrm{B}\left(18^{\circ} \mathrm{N}, 115^{\circ} \mathrm{E}\right.$, near the Dongsha Islands).

We present the 3-hourly WPD at the two stations, as shown in Figure 9. During this cold air process, the peak value of WPD at station A is higher than that at station B. But the stability at station $B$ is better.

The wave direction and grade of wave energy are the key factors in the exploitation of wave energy. We perform the first attempt to exhibit the "wave energy rose" during this cold air process on 12-17 March 2013, from which we can easily 

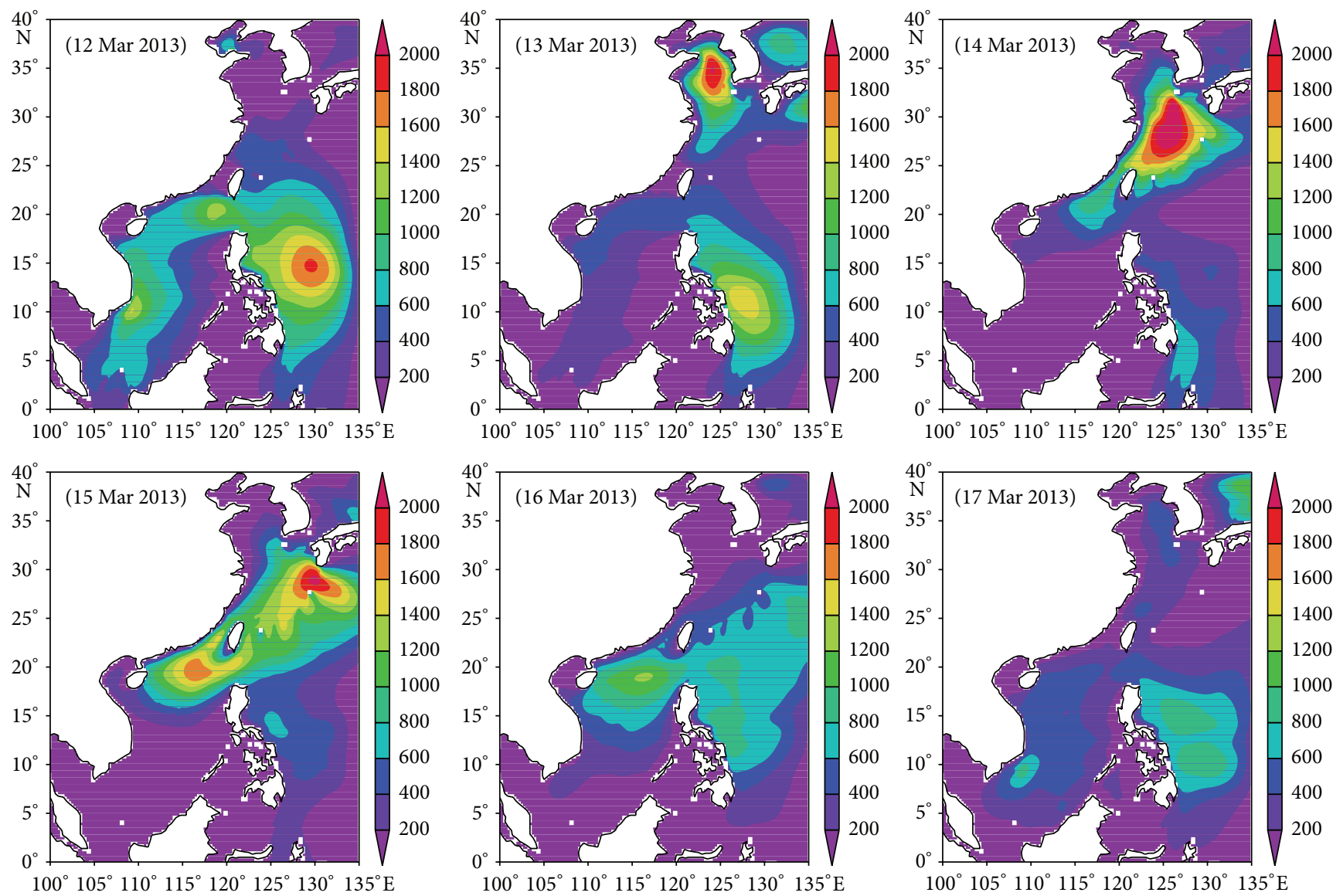

FIGURE 6: Daily total wave energy storage on 12-17 March 2013, unit: kWh/m.

find the main contribution of wave direction and WPD to the wave energy, as shown in Figure 10. It is very clear that the wave energy at station A is mainly contributed by the NW direction wave; particularly the occurrences of WPD 40$50 \mathrm{~kW} / \mathrm{m}$ and $50-60 \mathrm{~kW} / \mathrm{m}$ are high. At station $\mathrm{B}$, the wave energy is mainly contributed by NE and ENE direction wave. It should be noticed that, during the cold air process, the wave direction exhibits an arc shape along the coastal line.

\section{Conclusions}

This study produced a numerical forecasting experiment of the China Sea wave energy during two cold air processes on 12-17 March 2013, using WW3 wave model driven by T213 (WW3-T213) and T639 (WW3-T639) wind data separately. Then the WW3-T213 and WW3-T639 were verified and compared to build a short-term wave energy forecasting structure suited for the China Sea. Comprehensively considering the WPD, "wave energy rose," daily total storage of wave energy, daily effective storage of wave energy, and total storage and effective storage of wave energy in the next week, we also designed a series of short-term wave energy forecasting productions. The results show the following:

(1) Forced by the T213 and T639 forecasting wind fields, the WW3 wave model exhibits a good skill on the numerical forecasting of the China Sea WPD, while the result of WW3-T639 is much better. During the cold air process, the forecasting WPD has a good agreement with the observed WPD, except stations affected by the topography significantly, such as Qigu station in the southwest of Taiwan Island. The simulation ability of WW3 mode in the sea areas surrounding the Korean Peninsula and Japan is relatively better than that in the sea area surrounding Taiwan Island. The forecasting WPD is overall slightly smaller than the observed values, meaning that the actual wave energy is more promising than the forecasting condition.

(2) The cold air can bring a WPD of $>20 \mathrm{~kW} / \mathrm{m}$ (which is regarded as rich energy) in large scale area of the China Sea. Even more, as there are relatively frequent cold airs in winter, early spring, and late autumn in the China Sea and the surrounding waters, abundant wave energy ensues, meaning abundant wave energy resources in the China Sea.

(3) Judging from the daily total storage of wave energy, daily effective storage of wave energy, and the total storage and effective storage of wave energy in the next week start from one cold air process, abundant 

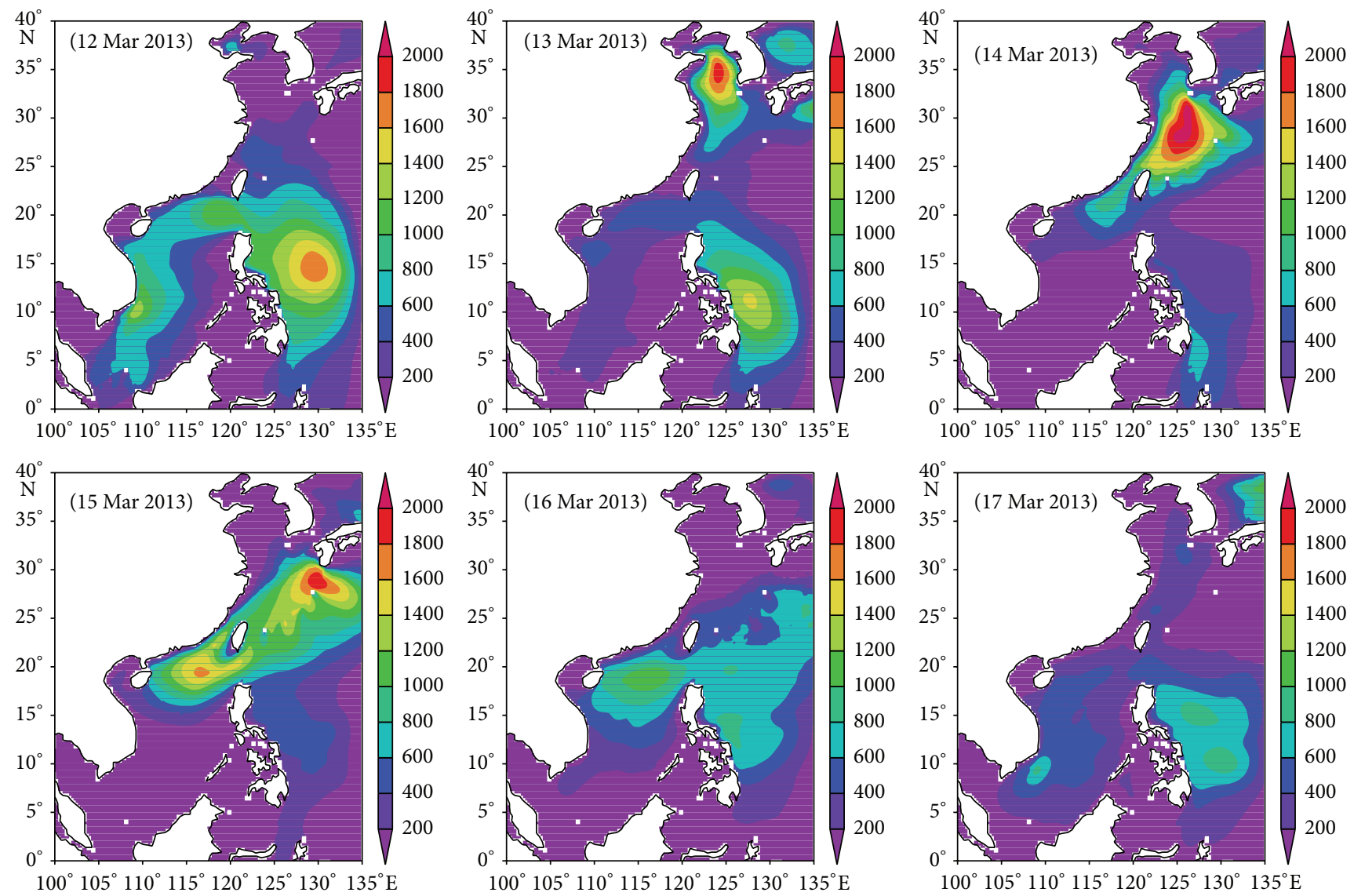

FIGURE 7: Daily effective storage of wave energy on 12-17 March 2013, unit: kWh/m.
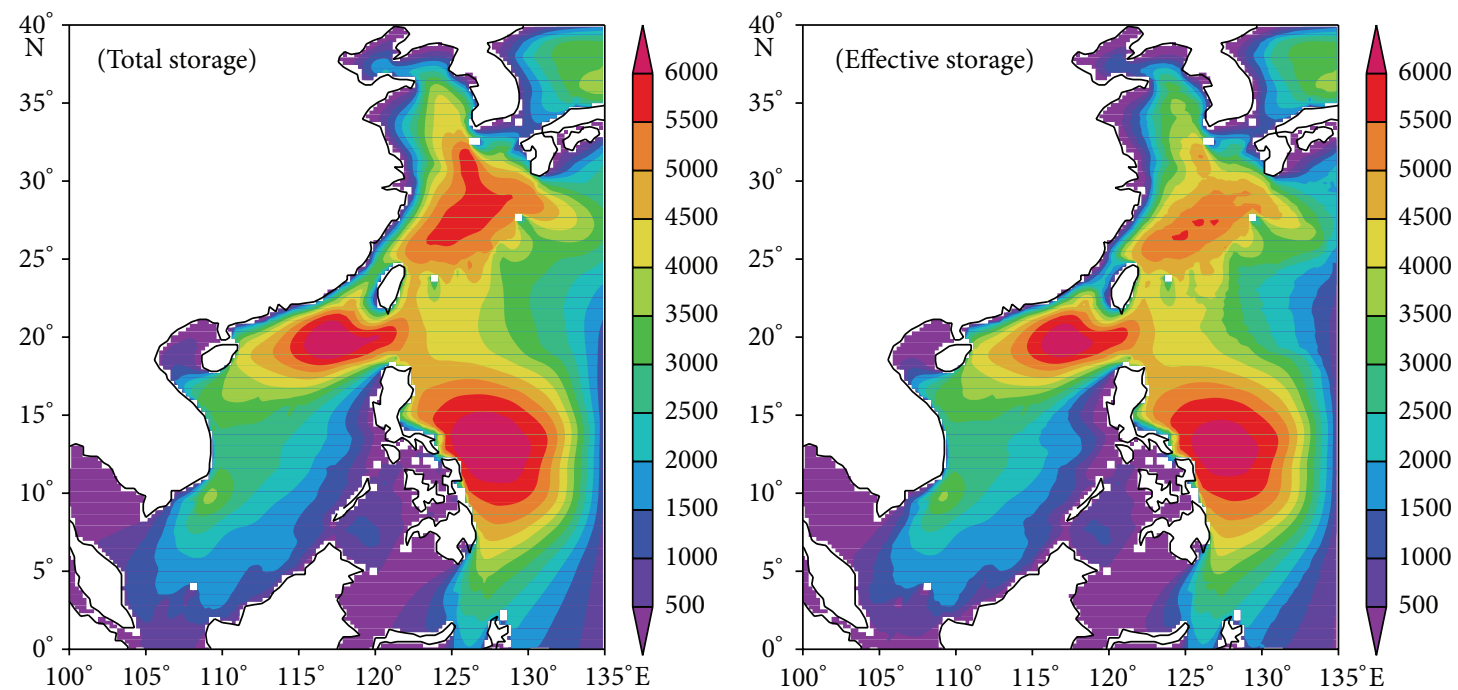

FIGURE 8: Total storage and effective storage of wave energy in the next week start from 12 March 2013, unit: kWh/m.

wave energy was found in the China Sea during the cold air process.

(4) From the "wave energy rose," it is clear that the wave energy at station A (at the Tsushima Strait) is mainly contributed by the NW direction wave; particularly the occurrences of WPD $40-50 \mathrm{~kW} / \mathrm{m}$ and 50-60 kW/m are high. At station B (near the Dongsha Islands), the wave energy is mainly contributed by $\mathrm{NE}$ and ENE direction wave. 


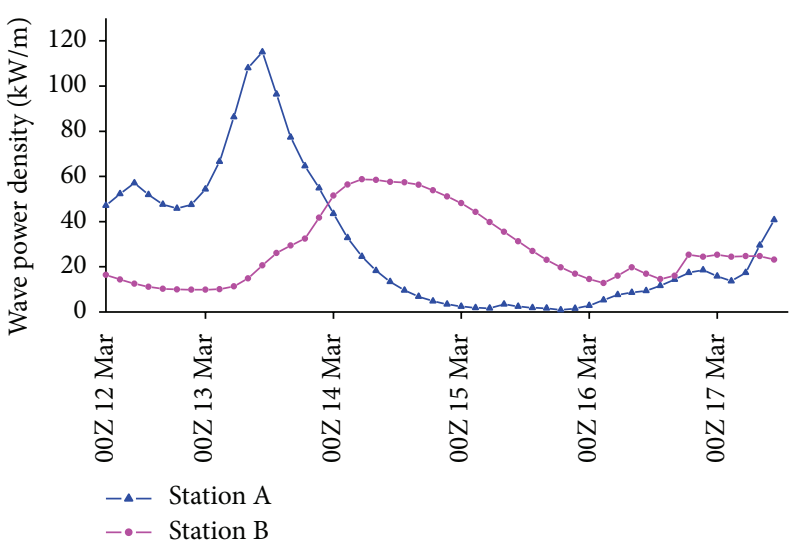

Figure 9: Wave power density at station A and station B on 12-17 March 2013.

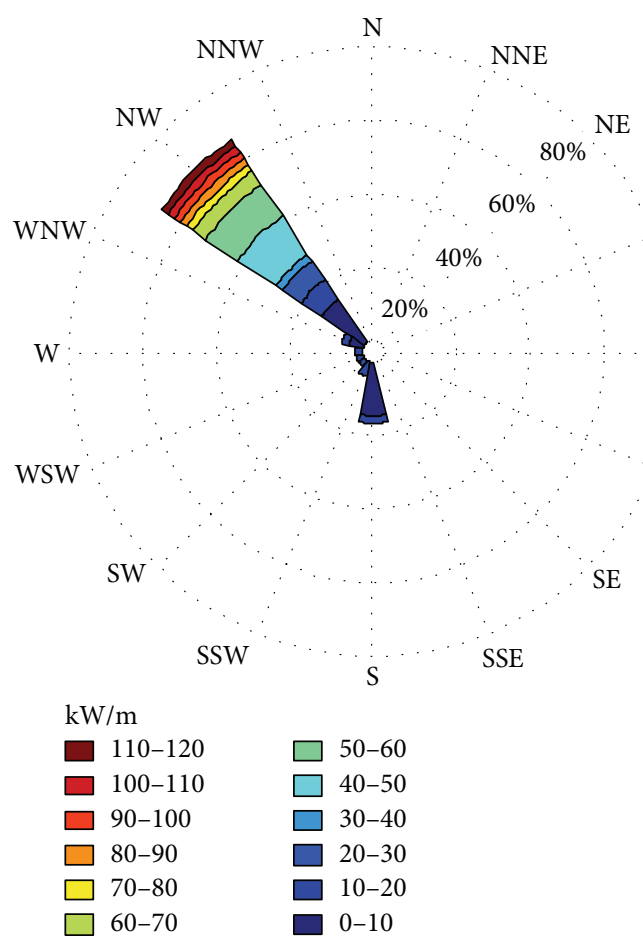

(a)

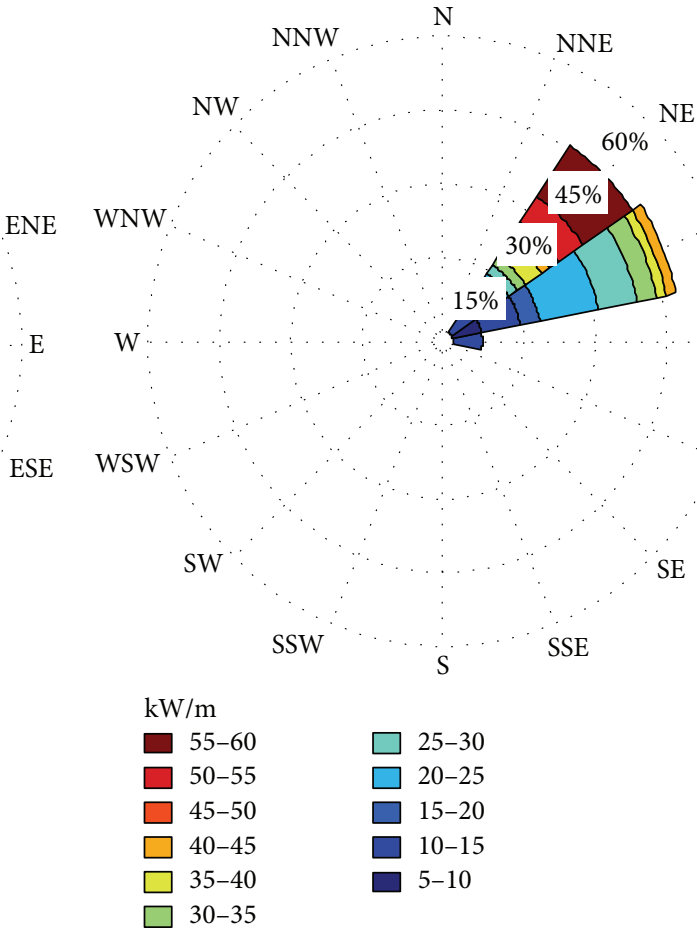

(b)

Figure 10: Wave energy rose at station A (a) and station B (b) on 12-17 March 2013.

\section{Nomenclature}

CC: $\quad$ Correlation coefficient

CCMP: Cross-Calibrated Multiplatform

MAE: Mean absolute error

NAO: North Atlantic Oscillation

RMSE: Root mean square error

SWAN: Simulated WAves Nearshore

T/P: $\quad$ TOPEX/Poseidon

WW3: WAVEWATCH-III.

\section{Competing Interests}

The authors declare that they have no competing interests.

\section{Acknowledgments}

This work was supported by the National Science Foundation for Young Scientists of China (Evaluation and Prediction of Wave Energy Resource in the South China Sea and North Indian Ocean), the National Key Basic Research Development Program, astronomy and earth factor on the impact of climate change (Grant no. 2012CB957803), and Asian regional sea air interaction mechanism and its role in global change (Grant no. 2010CB950400).

\section{References}

[1] A. Rashid and S. Hasanzadeh, "Status and potentials of offshore wave energy resources in Chahbahar area (NW Omman Sea)," 
Renewable and Sustainable Energy Reviews, vol. 15, no. 9, pp. 4876-4883, 2011.

[2] F. Chen, S.-M. Lu, K.-T. Tseng, S.-C. Lee, and E. Wang, "Assessment of renewable energy reserves in Taiwan," Renewable and Sustainable Energy Reviews, vol. 14, no. 9, pp. 2511-2528, 2010.

[3] L. Hammar, J. Ehnberg, A. Mavume, B. C. Cuamba, and S. Molander, "Renewable ocean energy in the Western Indian Ocean," Renewable and Sustainable Energy Reviews, vol. 16, no. 7, pp. 4938-4950, 2012.

[4] K. Gunn and C. Stock-Williams, "Quantifying the global wave power resource," Renewable Energy, vol. 44, pp. 296-304, 2012.

[5] R. Tornkvist, “Ocean wave power station," Report 28, Swedish Technical Scientific Academy, Helsinki, Finland, 1975.

[6] K. Hulls, "Wave power," The New Zealand Energy Journal, vol. 50, pp. 44-48, 1977.

[7] P. K. Robert and R. Mitchell, "Environmental implications of wave energy proposals for the outer hebrides and Moray Firth," Ocean Engineering, vol. 10, no. 6, pp. 459-469, 1983.

[8] M. T. Pontes, R. Aguiar, and H. O. Pires, "A nearshore wave energy atlas for Portugal," Journal of Offshore Mechanics and Arctic Engineering, vol. 127, no. 3, pp. 249-255, 2005.

[9] M. Folley, T. J. T. Whittaker, and A. Henry, "The effect of water depth on the performance of a small surging wave energy converter," Ocean Engineering, vol. 34, no. 8-9, pp. 1265-1274, 2007.

[10] A. Akpinar and M. I. H. Kömürcü, "Assessment of wave energy resource of the Black Sea based on 15-year numerical hindcast data," Applied Energy, vol. 101, pp. 502-512, 2013.

[11] S. P. Neill and M. R. Hashemi, "Wave power variability over the northwest European shelf seas," Applied Energy, vol. 106, pp. 3146, 2013.

[12] B. Roger, "Wave energy forecasting accuracy as a function of forecast time horizon," Tech. Rep. EPRI-WP-013, 2009, http://www.doc88.com/p-5334126229545.html.

[13] C.-W. Zheng, J. Pan, and J.-X. Li, "Assessing the China Sea wind energy and wave energy resources from 1988 to 2009," Ocean Engineering, vol. 65, pp. 39-48, 2013.

[14] C. W. Zheng, G. Lin, and L. T. Shao, "Frequency of rough sea and its long-term trend analysis in the China Sea from 1988 to 2010," Journal of Xiamen University, vol. 52, no. 3, pp. 395-399, 2013 (Chinese).

[15] C. W. Zheng and C. Y. Li, "Variation of the wave energy and significant wave height in the China Sea and adjacent waters," Renewable and Sustainable Energy Reviews, vol. 43, pp. 381-387, 2015.

[16] G. Iglesias and R. Carballo, "Choosing the site for the first wave farm in a region: a case study in the Galician Southwest (Spain)," Energy, vol. 36, no. 9, pp. 5525-5531, 2011.

[17] A. M. Cornett, "A global wave energy resource assessment," in Proceedings of the 18th International Offshore and Polar Engineering Conference (ISOPE '08), pp. 318-326, Vancouver, Canada, July 2008.

[18] A. Vosough, "Wave power," International Journal of Multidisciplinary Sciences and Engineering, vol. 2, no. 7, pp. 60-63, 2011.

[19] D. Xiao, L. T. Deng, J. Chen, and J. K. Hu, “Tentative verification and comparison of WRF forecasts driven by data from T213 and T639 models," Torrential Rain and Disasters, vol. 29, no. 1, pp. 20-29, 2010.

[20] S. H. Ma, Y. Wu, A. X. Qu, T. G. Xiao, and X. Li, "Comparative analysis on tropical cyclone numerical forecast errors of T213 and T639 models," Journal of Applied Meteorological Science, vol. 23, no. 2, pp. 167-173, 2012.

[21] P. C. Chu, Y. Qi, Y. Chen, P. Shi, and Q. Mao, "South China Sea wind-wave characteristics. Part 1: validation of wavematchIII using TOPEX/Poseidon data," Journal of Atmospheric and Oceanic Technology, vol. 21, no. 11, pp. 1718-1733, 2004.

[22] M. K. Li, Y. J. Hou, B. S. Yin, J. B. Song, and W. Zhao, "Numerical simulation of scatterometer assimilated wind and ocean wave in eastern China seas and adjacent waters," Chinese Journal of Oceanology and Limnology, vol. 24, no. 1, pp. 42-47, 2006.

[23] C. W. Zheng, J. Pan, and G. Huang, "Forecasting of the China Sea ditching probability using WW3 wave model," Journal of Beijing University of Aeronautics and Astronautics, vol. 40, no. 3, pp. 314-320, 2014 (Chinese). 

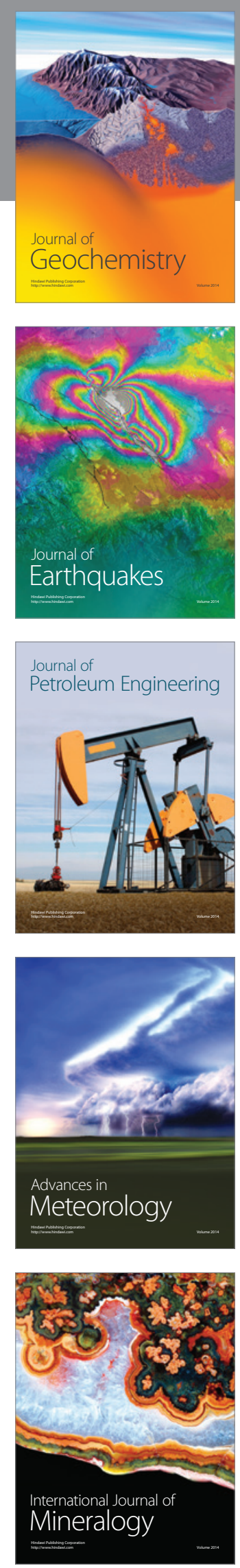
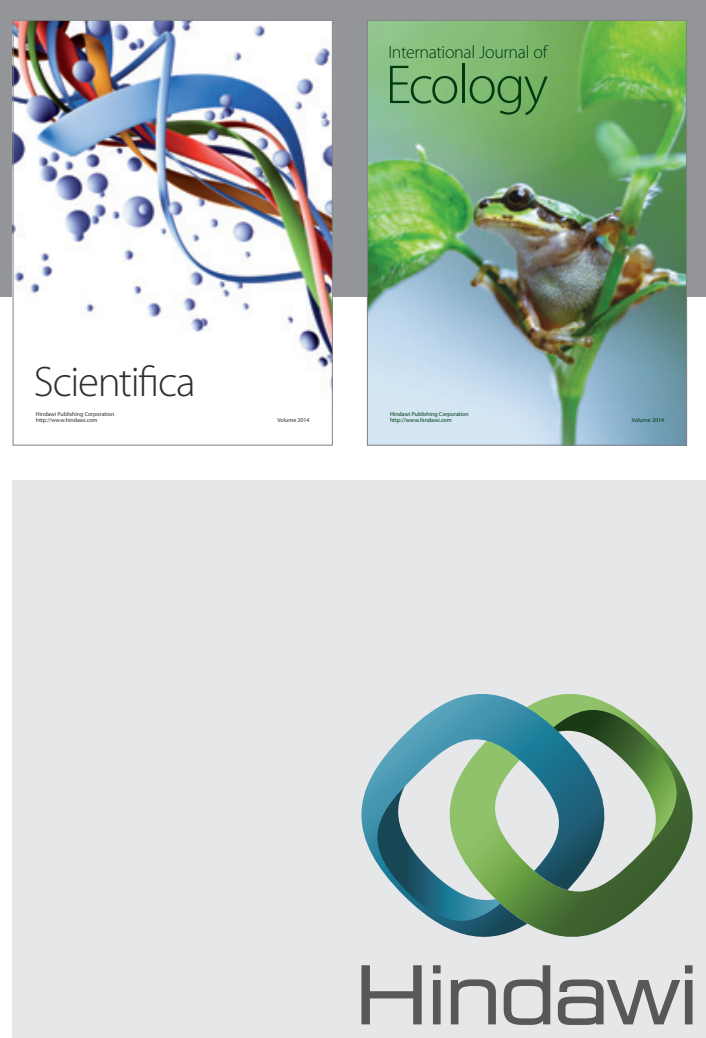

Submit your manuscripts at

http://www.hindawi.com
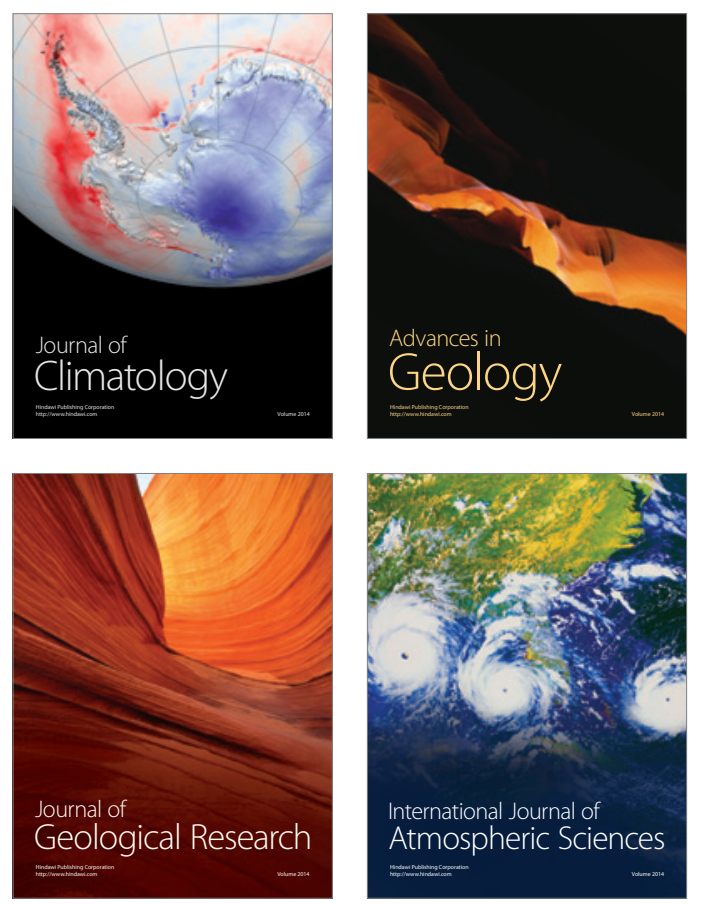

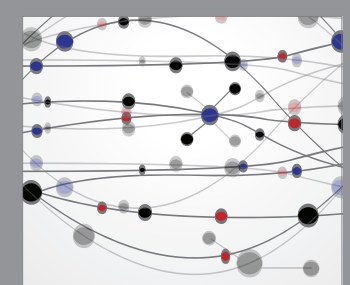

The Scientific

\section{World Journal}
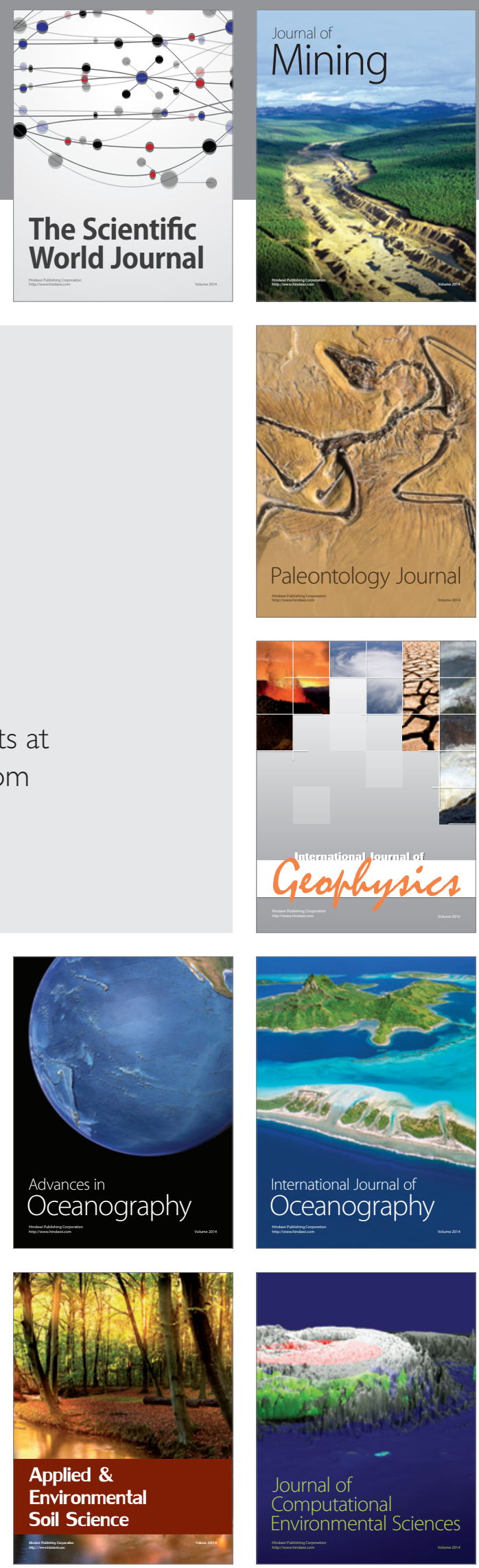